\title{
Adhesives: Test Method, Group Assignment, and Categorization Guide for High-Loading-Rate Applications
}

by Robert Jensen, Daniel DeSchepper, David Flanagan, Wendy Kosik Chaney, Jason Robinette, Gerard Chaney, and Charles Pergantis

ARL-SR-288

September 2017

ARL-ADHES-QA-001.00 rev 1.1 


\section{NOTICES}

\section{Disclaimers}

The findings in this report are not to be construed as an official Department of the Army position unless so designated by other authorized documents.

Citation of manufacturer's or trade names does not constitute an official endorsement or approval of the use thereof.

Destroy this report when it is no longer needed. Do not return it to the originator. 


\section{Army Research Laboratory}

Aberdeen Proving Ground, MD 21005-5069

\section{Adhesives: Test Method, Group Assignment, and Categorization Guide for High-Loading-Rate Applications}

Robert Jensen, Daniel DeSchepper, David Flanagan, Wendy Kosik Chaney, Jason Robinette, Gerard Chaney, and Charles Pergantis

Weapons and Materials Research Directorate, ARL Coatings, Corrosion and Engineering Polymers Branch (CCEPB)* *CCEPB is ISO 9001:2008 Certified by SRI Quality System Registrar 


\section{REPORT DOCUMENTATION PAGE}

Form Approved OMB No. 0704-0188

Public reporting burden for this collection of information is estimated to average 1 hour per response, including the time for reviewing instructions, searching existing data sources, gathering and maintaining the data needed, and completing and reviewing the collection information. Send comments regarding this burden estimate or any other aspect of this collection of information, including suggestions for reducing the burden, to Department of Defense, Washington Headquarters Services, Directorate for Information Operations and Reports (0704-0188), 1215 Jefferson Davis Highway, Suite 1204, Arlington, VA 22202-4302. Respondents should be aware that notwithstanding any other provision of law, no person shall be subject to any penalty for failing to comply with a collection of information if it does not display a currently valid OMB control number.

PLEASE DO NOT RETURN YOUR FORM TO THE ABOVE ADDRESS.

\begin{tabular}{|l|l|l|l}
\hline 1. REPORT DATE (DD-MM-YYYY) & 2. REPORT TYPE & 3. DATES COVERED (From - To)
\end{tabular}

\begin{tabular}{l|l} 
September 2017 & Final
\end{tabular}

4. TITLE AND SUBTITLE

November 2013-September 2017

Adhesives: Test Method, Group Assignment, and Categorization Guide for High-

Loading-Rate Applications 5a. CONTRACT NUMBER

5b. GRANT NUMBER

5c. PROGRAM ELEMENT NUMBER

6. AUTHOR(S)

Robert Jensen, Daniel DeSchepper, David Flanagan, Wendy Kosik Chaney, Jason

Robinette, Gerard Chaney, and Charles Pergantis

5d. PROJECT NUMBER

R.0010455.2.92

5e. TASK NUMBER

5f. WORK UNIT NUMBER

7. PERFORMING ORGANIZATION NAME(S) AND ADDRESS(ES)

U.S. Army Research Laboratory

ATTN: RDRL-WMM-C

Aberdeen Proving Ground, MD 21005-5069

9. SPONSORING/MONITORING AGENCY NAME(S) AND ADDRESS(ES)

\section{PERFORMING ORGANIZATION}

REPORT NUMBER

ARL-SR-288

ARL-ADHES-QA-001.00 rev 1.1

10. SPONSOR/MONITOR'S ACRONYM(S)

11. SPONSOR/MONITOR'S REPORT

NUMBER(S)

\section{DISTRIBUTION/AVAILABILITY STATEMENT}

Approved for public release; distribution is unlimited.

\section{SUPPLEMENTARY NOTES}

Send comments or inquiries to: usarmy.APG.arl.mbx.adhesive-research@mail.mil

\section{ABSTRACT}

This document provides guidance from within the Adhesives and Interfaces Research Team of the Coatings, Corrosion, \& Engineered Polymers Branch (CCEPB) and the U.S. Army Research Laboratory (ARL) for initial performance-based screening evaluation and grouping priority assignments/categorization of candidate adhesives for high-loading-rate applications relevant to U.S. Army needs.

\section{SUBJECT TERMS}

adhesive, testing, single lap joint, high loading rate, database, metadata, material pedigree

\begin{tabular}{|l|l|l|l|l|l|}
\hline \multicolumn{2}{|l|}{ 16. SECURITY CLASSIFICATION OF: } & $\begin{array}{l}\text { 17. LIMITATION } \\
\text { OF ABSTRACT }\end{array}$ & $\begin{array}{l}\text { 18. NUMBER } \\
\text { OF PAGES }\end{array}$ & $\begin{array}{l}\text { 19a. NAME OF RESPONSIBLE PERSON } \\
\text { Branch line (or See block 13) }\end{array}$ \\
\cline { 1 - 2 } $\begin{array}{l}\text { a. REPORT } \\
\text { Unclassified }\end{array}$ & $\begin{array}{l}\text { b. ABSTRACT } \\
\text { Unclassified }\end{array}$ & $\begin{array}{l}\text { c. THIS PAGE } \\
\text { Unclassified }\end{array}$ & UU & 20 & $\begin{array}{l}\text { 19b. TELEPHONE NUMBER (Include area code) } \\
410-306-1521\end{array}$ \\
\hline
\end{tabular}




\section{Contents}

List of Figures $\quad$ iv

$\begin{array}{llr}1.0 & \text { Purpose } & 3\end{array}$

$\begin{array}{lll}2.0 & \text { Scope } & 3\end{array}$

$\begin{array}{llr}3.0 & \text { Policy } & 3\end{array}$

$\begin{array}{lll}4.0 & \text { Responsibilities } & 3\end{array}$

$\begin{array}{lll}5.0 & \text { Requirements } & 3\end{array}$

$\begin{array}{lll}\text { 6.0 } & \text { Terms and Definitions } & 3\end{array}$

$\begin{array}{llr}7.0 & \text { Records } & 4\end{array}$

8.0 Method Used to Characterize and Evaluate Adhesives 4

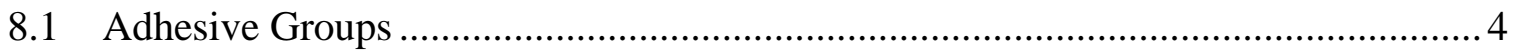

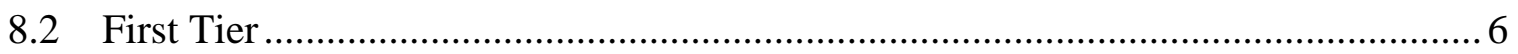

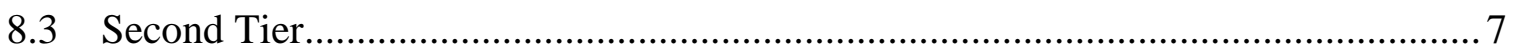

$\begin{array}{lll}9.0 & \text { References } & 9\end{array}$

$\begin{array}{lll}10.0 & \text { Appendix. Tier Progression Flow Chart } & 11\end{array}$

Amendment 001: ARL-ADHES-QA-001.00 rev 1.1 12

$\begin{array}{ll}\text { Distribution List } & 14\end{array}$ 


\section{List of Figures}

Figure 1. Adhesive groups based upon $\mathrm{S}_{\max }$ and $\mathrm{d}_{\text {failure }}$ single-lap-joint performance at RT (dry conditioning).

Figure 2. Illustration of the adhesively bonded single-lap-joint test specimen configuration (refer to ASTM D1002-10 for dimensions).

Figure 3. Graphical representation of $P_{\max }$ and $d_{\text {failure }}$ for a single-lap-joint tensile load versus displacement curve. 


\title{
Coatings, Corrosion, and Engineered Polymers Branch Standard Process Description (SPD)
}

\section{Adhesives: Test Method, Group Assignment, and Categorization Guide for High-Loading-Rate Applications}

\author{
ARL-ADHES-QA-001.00 rev 1.1 \\ Origin Date: 11/05/2013 \\ Rev. No. 1.1 Date: 9/07/2017 \\ Prepared by: \\ Robert Jensen \\ Daniel DeSchepper \\ David Flanagan \\ Wendy Kosik Chaney \\ Jason Robinette \\ Adhesives and Interfaces Research Team \\ Coatings, Corrosion, and Engineered Polymers Branch \\ Materials \& Manufacturing Science Division \\ U.S. Army Research Laboratory \\ RDRL-WMM-C \\ APG, MD 21005 \\ Send comments or inquiries to: usarmy.APG.arl.mbx.adhesive-research@mail.mil \\ Reviewed by: \\ CCEPB ISO 9001:2008 Working Group \\ Gerard Chaney \\ Charles Pergantis \\ Coatings, Corrosion, and Engineered Polymers Branch \\ Materials \& Manufacturing Science Division \\ U.S. Army Research Laboratory \\ RDRL-WMM-C \\ APG, MD 21005 \\ Approved by: \\ James Snyder (Chief, Acting) \\ Coatings, Corrosion, and Engineered Polymers Branch \\ Materials \& Manufacturing Science Division \\ U.S. Army Research Laboratory \\ RDRL-WMM-C \\ APG, MD 21005
}




\section{History of Changes*}

\section{Rev. No. Date Pages Description of Changes}

$0.1 \quad 11 / 05 / 2013$

$1.0 \quad 06 / 06 / 2014$

$1.1 \quad 06 / 30 / 2017$
First draft prepared by Adhesives and Interfaces Research Team. Document not OPSEC approved for release.

Technically reviewed by two ARL reviewers external to the Adhesives and Interfaces Research Team. Reviewed by Chief, CCEPB. OPSEC approved for public release; distribution unlimited. Administrative and operational procedures for continuation beyond the Second Tier of testing and characterization are omitted. Simultaneously released as ARL-SR-288.

Decreased single-lap-joint strength retention at elevated temperature from $75 \%$ to $50 \%$ of dry maximum strength, per 8.3.2.1, as proposed by experimental results discussed in ARL-TR-8011. ${ }^{\dagger}$

Technically reviewed by two ARL reviewers external to the Adhesives and Interfaces Research Team. Reviewed by Chief, CCEPB. OPSEC approved for public release; distribution unlimited. Administrative and operational procedures for continuation beyond the Second Tier of testing and characterization are omitted. Simultaneously released as an amended version of ARL-SR-288.

\section{Authorization Signatures}

Originator: Pobert\& Densen Date: $9 / 7 / 17$
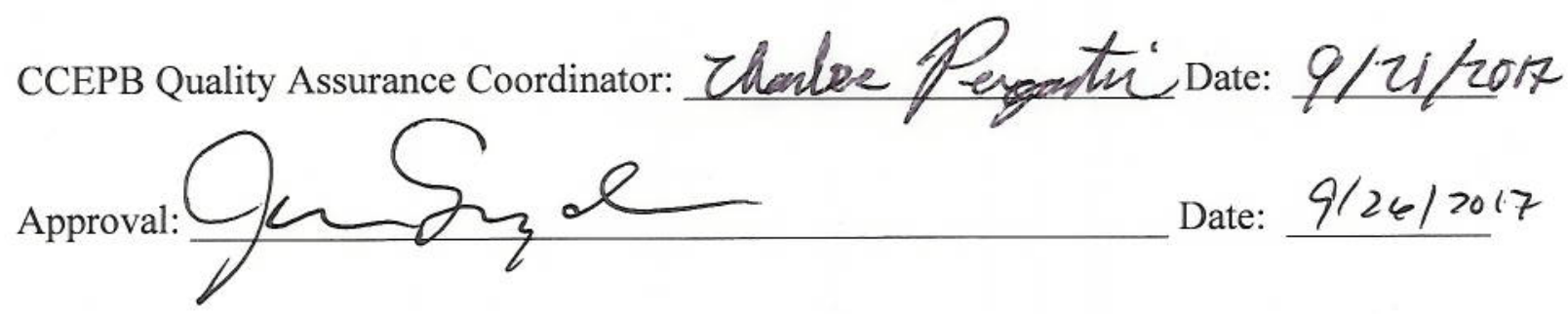

\footnotetext{
${ }^{*}$ Refer to Document Types and Naming Conventions (LHC-PM-QA-202.00 rev 1.2, CERN, Geneva Switzerland) for formatting recommendations.

† Jensen R, Flanagan D, DeSchepper D, Silton M. Single-Lap-Joint Screening of Hysol EA 9309NA Epoxy Adhesive. Aberdeen Proving Ground (MD): Army Research Laboratory (US); 2017 May. Report No.: ARL-TR-8011.
} 


\subsection{Purpose}

This document provides guidance from within the Adhesives and Interfaces Research Team of the Coatings, Corrosion, \& Engineered Polymers Branch (CCEPB) and the U.S. Army Research Laboratory (ARL) for initial performance-based screening evaluation and grouping priority assignments/categorization of candidate adhesives for high-loading-rate applications relevant to U.S. Army needs.

\subsection{Scope}

This standard process description (SPD) provides a guideline for assessing adhesives in the CCEPB. This SPD is not intended for acquisition acceptance. Rather, adhesives are screened for potential usage over a very broad performance spectrum to provide Army engineers, scientists, and researchers with the direction needed to meet operational priorities in a timely manner. Any deviation from the process details must be justified, fully documented, and submitted to the governing authority.

\subsection{Policy}

This SPD applies to all personnel developing, fabricating, testing, characterizing, and evaluating adhesives for bonding applications within the CCEPB.

\subsection{Responsibilities}

The Branch Chief, CCEPB, Adhesives Team leader, and principal investigator(s) will ensure all personnel working on adhesives development, fabrication, testing, characterization, and evaluation have full knowledge and/or proper training of this process, including equipment usage/operation test procedures and safety issues/factors before commencing relevant work within the CCEPB.

\subsection{Requirements}

All researchers performing adhesives development and evaluation work in the CCEPB must follow the procedures described within this SPD.

\subsection{Terms and Definitions}

For the purposes of this document, the following terms and definitions apply.

Database: As stated within ISO/IEC 2382-17:1999, a database shall be "a collection of data organized according to a conceptual structure describing the characteristics of these data and relationships among their corresponding entities, supporting one or more application areas." 1

Digital Archive: The term "digital archive” shall be referred to as an electronic repository of digital data and metadata "to preserve the authenticity, reliability, integrity, and usability of such records” as stated in ISO 13008:2012(E). ${ }^{2}$

Group: The term "group," when referring to adhesives, shall be defined as a collection of adhesives meeting designated property requirements; the term is based upon recognized testing standards. Group requirements are intended to show correlation against response measured in nonstandard Army testing configurations. For example, the groups defined in this SPD define property regions from bonded single-lap-joint tensile tests with performance in bonded armor configurations tested against ballistic threats. Grouping assignments/categorizations of adhesives are intended to be amendable as Army needs 
change or are further refined. The grouping assignment/categorization is independent of the adhesive's chemical, processing, application, and property data and is based exclusively on single-lap-joint tensile data and performance. Multiple grouping assignments/categorizations for a given adhesive are possible under this convention. Therefore, an adhesive could potentially be assigned simultaneous high- and low-priority groups in differing SPDs, depending on the chemical, processing, application, or property data used in the specific correlation. For example, adhesive requirements for armor and munitions applications typically weigh importance to differing properties. Grouping requirements/categorizations are specified using conventionally accepted testing standards, which are elaborated upon further within this SPD. The intention is to facilitate communication of U.S. Army-specific property requirements for research and development to industry, as well as academia.

Material Pedigree: The term "material pedigree" shall refer to the documentation used to ensure the traceability of an adhesive and its constitutive formulation ingredients to the original manufacturer. ${ }^{3}$

Metadata: Per ISO/IEC 2382-17:1999, the term "metadata" pertains to "data elements, possibly including their data descriptions, and data about data ownership, access paths, access rights and data volatility."1

Tier: The term "tier" shall be considered a layer of testing protocols used to progressively characterize adhesive response. Each successive tier level requires an increasing investment commitment because of increasing experimental and analysis complexity.

\subsection{Records}

Per Army Regulation (AR) 25-400-2, all records (including data and associated metadata) are assumed to "have value beyond the business process, such as for historical, lessons learned, or research purposes; these are generally long-term records." Records will be kept in physical laboratory notebooks and digitally archived for permanent retention, consistent with AR 25-4002 code "TP" (i.e., Transfer Permanent). ${ }^{4}$

\subsection{Method Used to Characterize and Evaluate Adhesives}

The method to characterize and evaluate an adhesive is a tiered system approach, whereby the adhesive is characterized and evaluated through standardized tests following a progression of increasing experimental difficulty. The First Tier testing represents an initial screening level for the candidate adhesive, which must be passed to warrant further investment in the progressively more involved higher-tier screening levels. Advancement through the testing tiers is entrusted to the discretion of the researcher(s). The testing standards referenced in each tier are used as guidelines and should be followed when applicable. Deviations from the testing standards must be fully noted and accepted by the governing authority.

\subsection{Adhesive Groups}

Adhesives will be assigned and categorized according to the following groups based on single-lapjoint tensile performance at room temperature (RT) under dry conditioning per sample preparation and testing procedures specified in ASTM D1002-10 (Standard Test Method for Apparent Shear Strength of Single-Lap-Joint Adhesively Bonded Metal Specimens by Tension Loading [Metalto-Metal]). ${ }^{5}$ Samples are to be stored in a desiccator cabinet or sealed in moisture-resistant sample bags immediately following sample preparation, with continued moisture-free storage until testing. 
Displacement at failure is not specified in ASTM D1002-10 but is required for grouping assignment/categorizing in this SPD and shall be defined as the following:

Group I: Group I adhesives shall be categorized as having a maximum strength greater than or equal to $10.0 \mathrm{MPa}(1450 \mathrm{psi})$ and a minimum complete failure displacement limit greater than $3.81 \mathrm{~mm}(0.15 \mathrm{in})$; (e.g., $d_{\text {failure }}>3.81 \mathrm{~mm}[0.15 \mathrm{in}]$ and $S_{\max } \geq 10.0 \mathrm{MPa}$ [1450 psi]).

Group II: Group II adhesives shall be categorized as also having a maximum strength greater than or equal to $10.0 \mathrm{MPa}(1450 \mathrm{psi})$, yet their complete failure displacement limits fall between the range of greater than or equal to $1.60 \mathrm{~mm}(0.063 \mathrm{in})$ and less than or equal to $3.81 \mathrm{~mm}$ (0.15 in); (e.g., $1.60 \mathrm{~mm}$ [0.063 in] $\leq d_{\text {failure }} \leq 3.81 \mathrm{~mm}[0.15 \mathrm{in}]$ and $S_{\max } \geq$ 10.0 MPa [1450 psi]).

Group III: Group III adhesives shall be categorized with a maximum strength greater than or equal to $10.0 \mathrm{MPa}(1450 \mathrm{psi})$ but producing complete failures at a displacement less than $1.60 \mathrm{~mm}$ (0.063 in); (e.g., $d_{\text {failure }}<1.60 \mathrm{~mm}$ [0.063 in], $\left.S_{\max } \geq 10.0 \mathrm{MPa}[1450 \mathrm{psi}]\right)$.

Group IV: Group IV adhesives shall be categorized as having a maximum strength less than 10.0 MPa (1450 psi) regardless of the amount of displacement at complete failure.

Adhesive grouping rejoins associated with their maximum strength versus displacement at complete failure is represented in Figure 1.

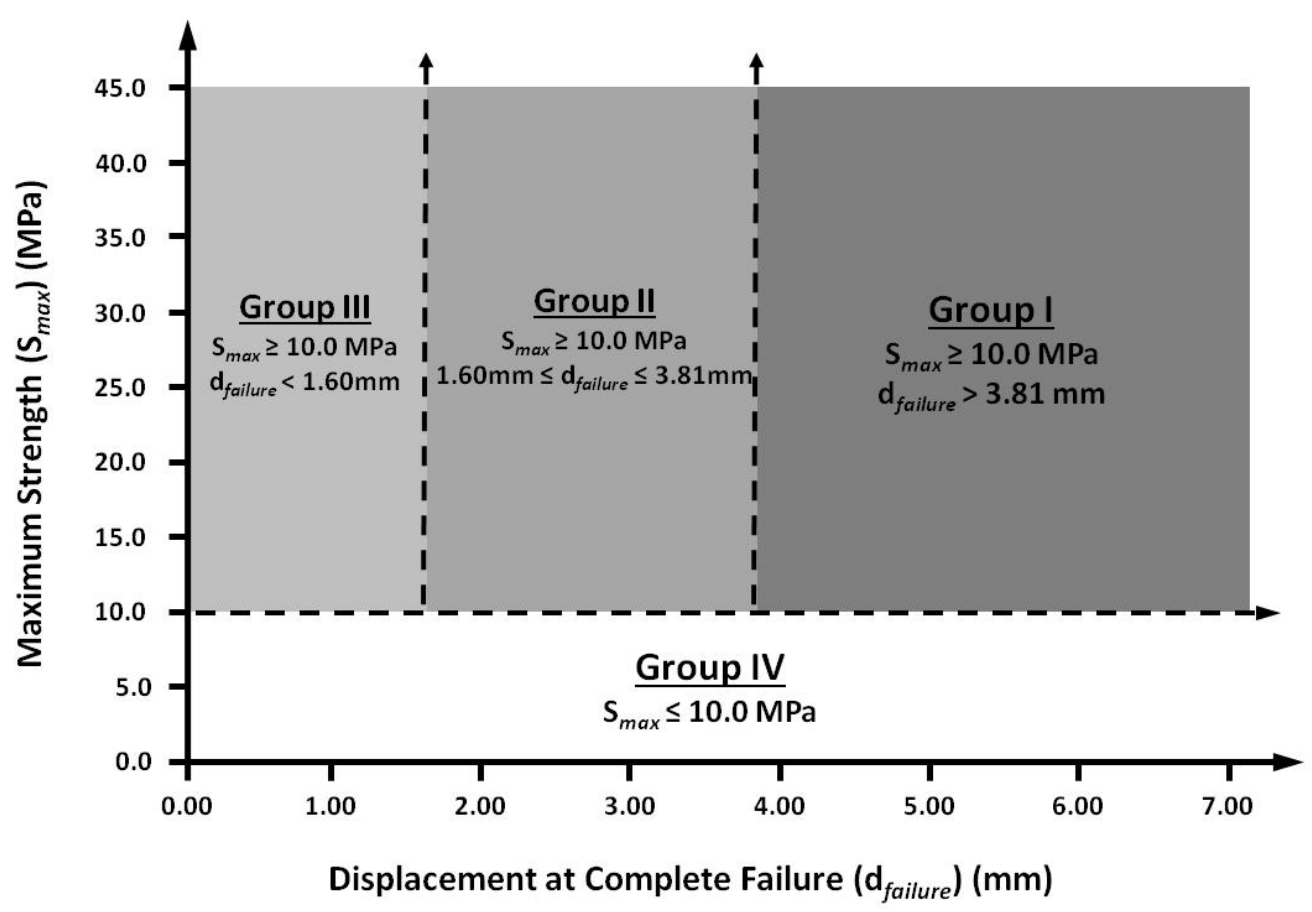

Figure 1. Adhesive groups based upon $\mathrm{S}_{\max }$ and $\mathrm{d}_{\text {failure }}$ single-lap-joint performance at RT (dry conditioning). 


\section{2 $\quad$ First Tier}

The First Tier of tests involves collecting the material's pedigree and determining adhesive properties via the standard single-lap-joint tensile test conducted at RT per ASTM D1002-10. Adhesives tested under first tier screening shall be assigned an initial grouping number associated with their performance (i.e., Group I, Group II, Group III, or Group IV).

\subsubsection{Material Pedigree}

The purpose of documenting the pedigree of the adhesive material is to gather and identify the original manufacturer's technical data sheet (TDS) and material safety data sheet (MSDS) information as references for the subsequent digitally archived experimental data. "Tagging” the TDS and MSDS to the adhesive allows for future tracking through public domain searches in the event that the original manufacturer is no longer viable or existent. In addition, material pedigree documentation is also required for adhesive formulations originating from academia due to student graduation. Furthermore, material pedigree data will also be documented and digitally archived for all ARL-developed adhesive formulations.

\subsubsection{Single-Lap-Joint Test at Room Temperature (Dry Conditioning)}

The single-lap-joint test specimen per ASTM D1002-10 is a convenient geometry for screening adhesive performance. An illustration of a typical test specimen is shown in Figure 2. The distribution of stress is nonuniform, ${ }^{6}$ and fundamental constitutive adhesive properties are difficult to derive. However, the overwhelming experimental simplicity, with respect to both fabrication and testing, heavily favors the single-lap-joint geometry as an initial screening configuration. ${ }^{7}$ Likewise, this joint geometry has also been studied extensively by academia, with numerous peerreviewed literature results and modeling strategies available for comparison. ${ }^{8}$ The single-lap-joint is also a favored industry standard.

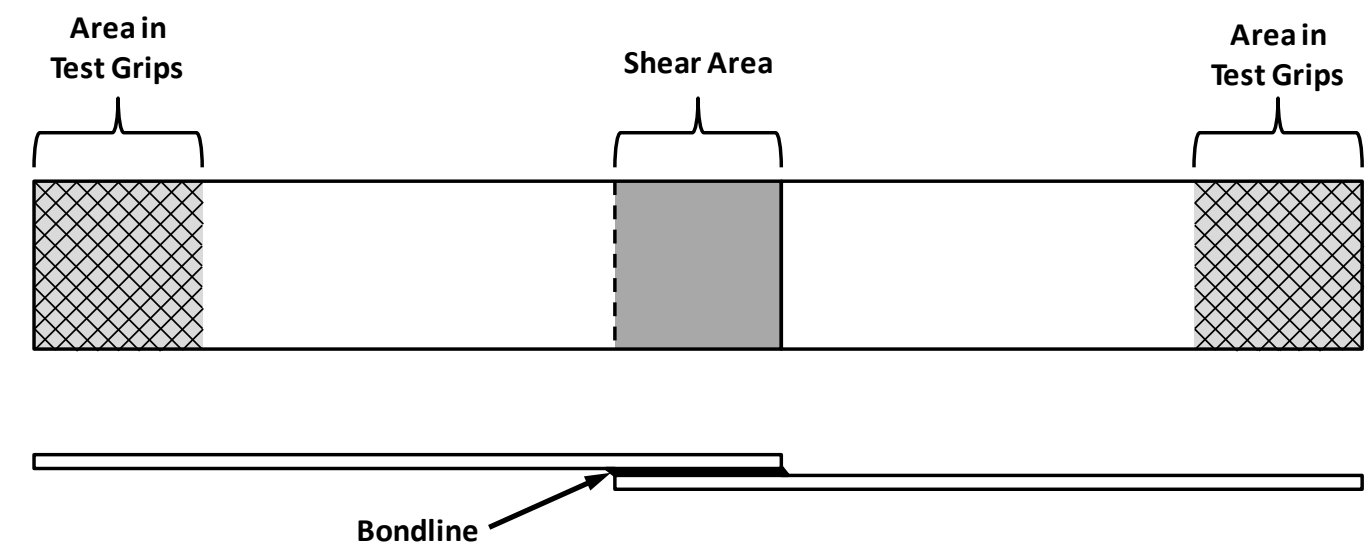

Figure 2. Illustration of the adhesively bonded single-lap-joint test specimen configuration (refer to ASTM D1002-10 for dimensions).

The specimen is placed within a mechanical testing machine and held into place at its ends by mechanical grips. Tensile load is applied until the joint fails. The maximum tensile strength $\left(S_{\max }\right)$ of the adhesive joint is defined as the maximum load $\left(P_{\max }\right)$ per shear area. Displacement at failure $\left(d_{\text {failure }}\right)$ is taken directly from the crosshead displacement of the testing machine. A typical load versus displacement curve showing $P_{\max }$ and $d_{\text {failure }}$ is illustrated graphically in Figure 3. 


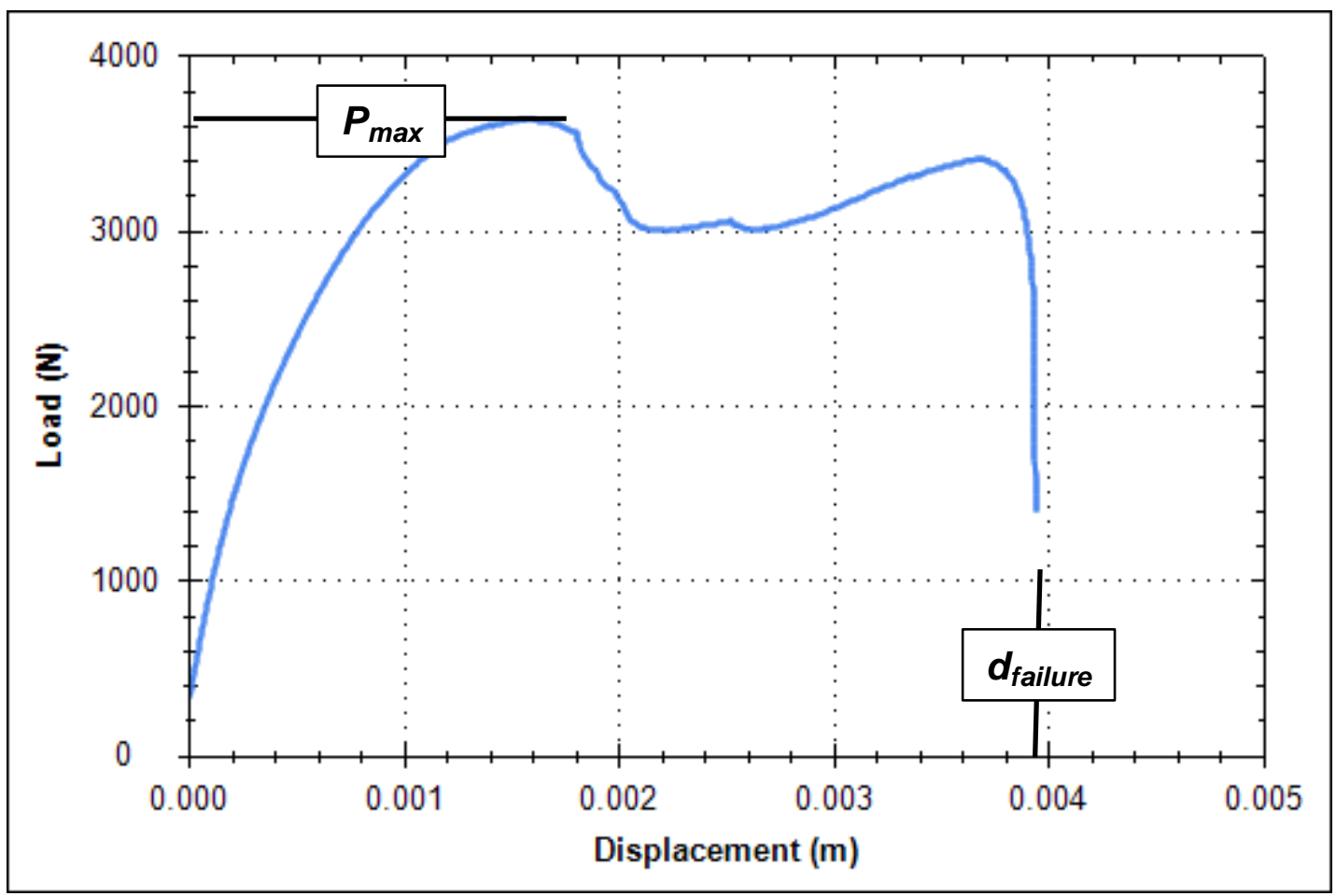

Figure 3. Graphical representation of $P_{\max }$ and $d_{\text {failure }}$ for a single-lap-joint tensile load versus displacement curve.

\subsection{Second Tier}

The Second Tier testing comprises fabricating additional single-lap-joint specimens to satisfy additional testing requirements under two different environmental loading conditions, which shall consist of hot and hot/wet conditioning environments. It is at the discretion of the researcher(s) if they care to fabricate all test specimens and generate data for the first and second tiers simultaneously. In some instances this may be acceptable, but others may require a more stepwise approach because of availability of resources, funding, and manpower. To be accepted for third tier testing, adhesives must pass second tier part one and part two requirements.

\subsubsection{Single-Lap-Joint Testing After Hot/Wet Conditioning}

This first part of the second tier test requires submersion of lap-joint specimens (i.e., non-ambient moisture conditioning) in a water immersion tank for fourteen (14) days at a constant temperature of $63^{\circ} \mathrm{C},+/-3^{\circ} \mathrm{C}\left(145^{\circ} \mathrm{F},+/-5^{\circ} \mathrm{F}\right)$. At the completion of the conditioning, specimens will be patdried and tested no later than thirty (30) minutes after being removed from the water immersion tank. As in the first tier, single-lap-joint tensile test data will be obtained via a mechanical testing machine at RT and at ambient air conditions as per ASTM D1002-10. Test duration and conditioning temperature is based upon considerations referenced in MIL-STD-810G, Laboratory Test Method 507.5, Humidity. ${ }^{9}$ Experimental technique considerations can be found in ASTM D5229/D5229M-12 (Standard Test Method for Moisture Absorption Properties and Equilibrium Conditioning of Polymer Matrix Composite Materials) ${ }^{10}$, ASTM D1151-00 (2013) (Standard Practice for Effect of Moisture and Temperature on Adhesive Bonds) ${ }^{11}$, and ASTM E865-12 (Standard Specification for Structural Film Adhesives for Honeycomb Sandwich Panels). ${ }^{12}$ 


\subsubsection{Requirements}

Acceptance to the next tier of testing requires that second tier, part one conditioned adhesives retain a minimum of $75 \%$ of their initial dry maximum strength measured in first tier testing, section 8.2.2. It is important to note that group assignment/categorization is entirely based upon the initial $S_{\max }$ and $d_{\text {failure }}$ at RT at dry conditioning. Displacement at failure following hot/wet conditioning will be digitally archived but will not alter the First Tier group determination. Likewise, if $S_{\max }$ (RT, dry) for a given Group I, II, or III adhesive is at or just above $10.0 \mathrm{MPa}$ (1450 psi) then measurement of the 75\% strength retention following hot/wet conditioning will not reassign the adhesive to Group IV.

\subsubsection{Single-Lap-Joint Testing at Elevated Temperature}

Second tier, part two, tests shall progress by testing fabricated samples to an elevated temperature condition of $71{ }^{\circ} \mathrm{C},+/-3{ }^{\circ} \mathrm{C}\left(160{ }^{\circ} \mathrm{F},+/-5{ }^{\circ} \mathrm{F}\right)$ using an in situ heated test chamber on the mechanical testing frame. Prior to loading specimens, the test chamber shall be heated for at least forty five (45) minutes to ensure the chamber air and mechanical components of the mechanical testing machine, such as grips, are at temperature and are stable, as measured by a thermocouple probe/sensor. Once a sample is loaded within the heated chamber, but prior to tensile testing, it shall be held in situ for at least ten (10) minutes until it reaches temperature equilibrium and is stable as measured by a thermocouple probe/sensor. The temperature of the test is based upon considerations referenced in MIL-STD-810G, Laboratory Test Method 501.5, High Temperature. ${ }^{13}$ Experimental technique considerations can be found in ASTM D1151-00(2013) (Standard Practice for Effect of Moisture and Temperature on Adhesive Bonds) ${ }^{11}$ and ASTM E865-12 (Standard Specification for Structural Film Adhesives for Honeycomb Sandwich Panels). ${ }^{12}$

\subsubsection{Requirements}

Acceptance to the next tier of testing also requires that second tier, part two conditioned adhesives retain a minimum of $50 \%$ of their dry maximum strength as measured in section 8.2.2. As in section 8.3.1.1, group assignments/categorizations are based upon the initial $S_{\text {max }}$ and $d_{\text {failure }}$ at RT and dry conditioning results. Displacement at failure at elevated temperature will be digitally archived but will not alter the First Tier group determination. Likewise, if $S_{\max }$ (RT, dry) for a given Group I, II, or III adhesive is at or just above $10.0 \mathrm{MPa}$ (1450 psi), then measurement of the $50 \%$ strength retention at elevated temperature will not reassign the adhesive to Group IV.

Adhesives that pass both second tier part one and part two requirements may be considered for additional ARL Third Tier testing. Test data and metadata for adhesives that do not pass both second tier part one and part two requirements will still be retained in a digital archive to (1) allow for data to be matched against alternative SPD requirements (both public releasable and restricted distribution), (2) enable sharing of nonproprietary commercial and academic data to other DoD organizations with either similar or differing adhesive requirements, and (3) enable a feedback mechanism with commercial and academic formulators, specifically in determining where the requirements specified by ARL-ADHES-QA-001.00 rev 1.1 are difficult to meet. Such "lessons learned” could have potential value in addressing future research focus.

Testing progression protocols beyond the third tier are intended for ARL administrative/ operational use only. 


\subsection{References}

1. ISO/IEC 2382-17:1999 “Information technology - Vocabulary - Part 17: Databases.” International Organization for Standardization/International Electrotechnical Commission, Geneva, Switzerland, 1999, www.iso.org 2. ISO 13008:2012(E) “Information and documentation - Digital records conversion migration process.” International Organization for Standardization, Geneva, Switzerland, 2012, www.iso.org

3. “Materials data management”, https://en.wikipedia.org/wiki/Materials_data_management, retrieved February 7, 2014.

4. Army Regulation 25-400-2 "Information Management: The Army Records Information Management System (ARIMS)”, Headquarters, Department of the Army, Washington, DC, 2 October 2007.

5. ASTM Standard D1002-10 "Standard Test Method for Apparent Shear Strength of Single-Lap-Joint Adhesively Bonded Metal Specimens by Tension Loading (Metal-to-Metal)." ASTM International, West Conshohocken, PA, 2010, DOI: 10.1520/D1002-10, www.astm.org

6. Volkersen, O. "Die Niektraftverteilung in Zugbeanspruchten Nietverbindungen mit Konstanten Laschenquerschnitten.” Luftfahrtforschung 15 (1938): 41-47.

7. ASTM Standard D4896-01(2008)e1 "Standard Guide for Use of Adhesive-Bonded Single Lap-Joint Specimen Test Results." ASTM International, West Conshohocken, PA, 2008, DOI: 10.1520/D4896-01R08E01, www.astm.org

8. da Silva LFM; das Neves PJC; Adams RD; Spelt JK “Analytical Models of Adhesively Bonded Joints-Part I: Literature Survey.” International Journal of Adhesion and Adhesives 29 (2009) 319-330.

9. Department of Defense Test Method Standard, "Environmental Engineering Considerations and Laboratory Tests.” MIL-STD-810G, Laboratory Test Method 507.5, Humidity, 31 October 2008, superseding MIL-STD-810F 1 January 2000.

10. ASTM Standard D5229/D5229M-12 "Standard Test Method for Moisture Absorption Properties and Equilibrium Conditioning of Polymer Matrix Composite Materials." ASTM International, West Conshohocken, PA, 2012, DOI: 10.1520/D5229_D5229M-12, www.astm.org

11. ASTM Standard D1151 - 00(2013) "Standard Practice for Effect of Moisture and Temperature on Adhesive Bonds." ASTM International, West Conshohocken, PA, 2013, DOI: 10.1520/D1151, www.astm.org 12. ASTM Standard E865-12 "Standard Specification for Structural Film Adhesives for Honeycomb Sandwich Panels." ASTM International, West Conshohocken, PA, 2012, DOI: 10.1520/E0865-12, www.astm.org 13. Department of Defense Test Method Standard, "Environmental Engineering Considerations and Laboratory Tests.” MIL-STD-810G, Laboratory Test Method 501.5, High Temperature, 31 October 2008, superseding MILSTD-810F 1 January 2000.

14. AMS Standard 3695 “Adhesive Film, Epoxy-Base For High Durability Structural Adhesive Bonding.” SAE International, Warrendale, PA, 1983, Reaffirmed 2014.

15. AMS Standard 3695 “Adhesive Film, Epoxy-Base, High Durability For $95^{\circ} \mathrm{C}\left(200{ }^{\circ} \mathrm{F}\right)$ Service.” SAE International, Warrendale, PA, 1983, Reaffirmed 2014. 
ARL-ADHES-QA-001.00 rev 1.1

INTENTIONALLY LEFT BLANK. 


\subsection{Appendix. Tier Progression Flow Chart}

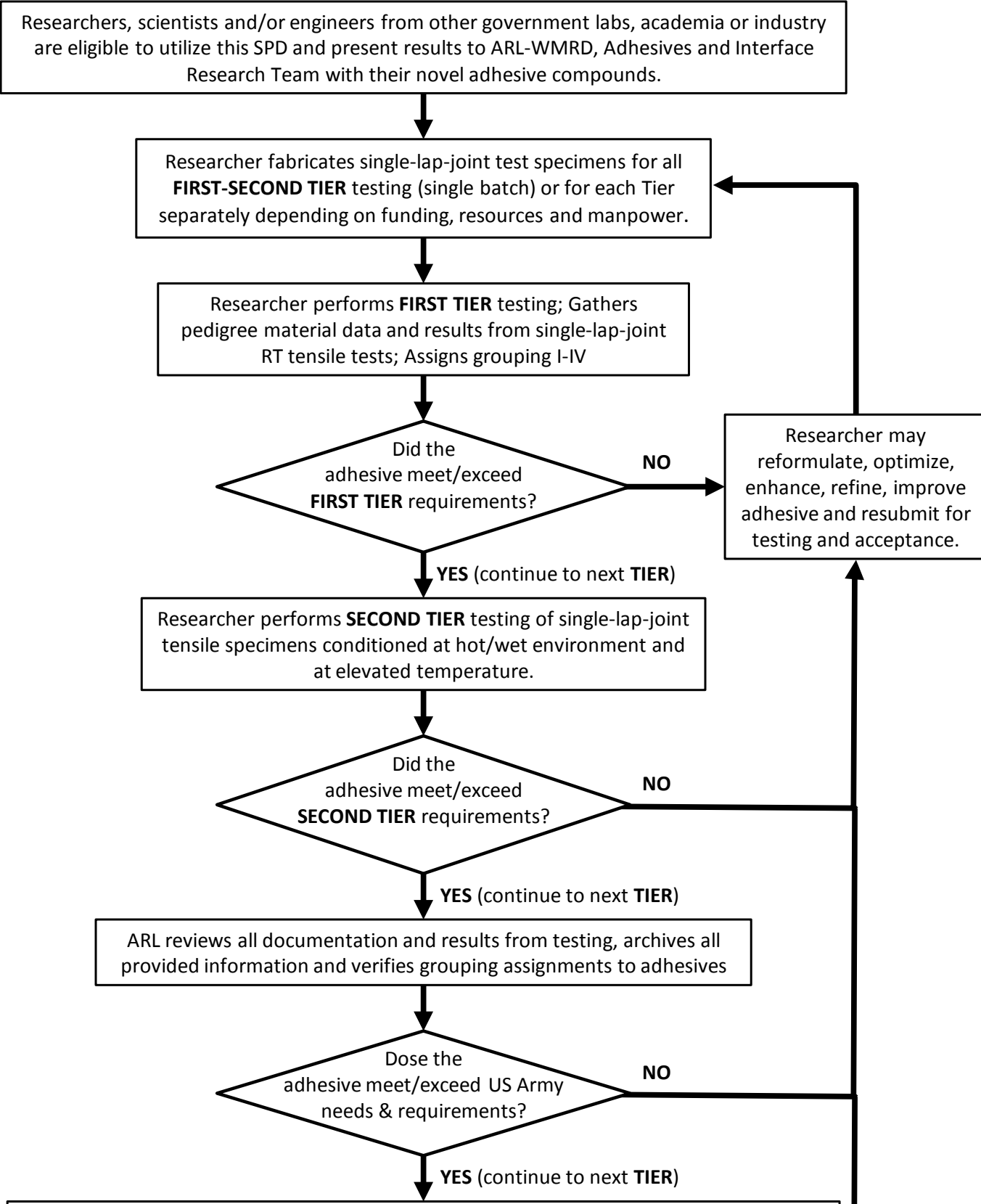

ARL optionally funds \& conducts additional testing, independently reviews all results, archives all data/metadata; determines if adhesive satisfies an Army need.

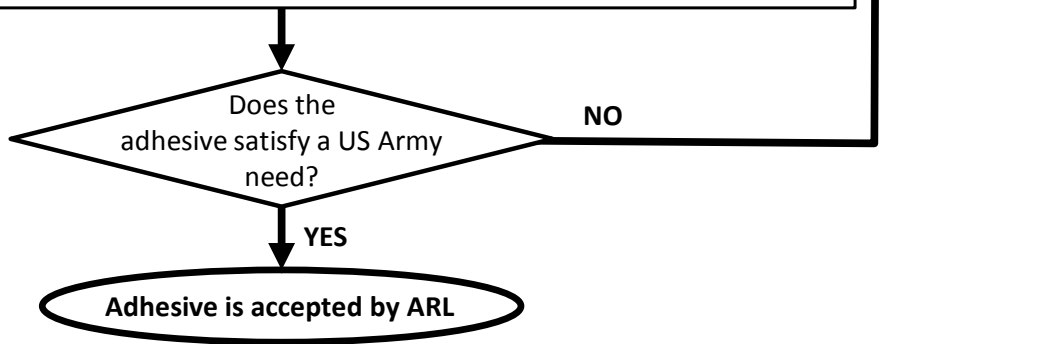




\title{
AMENDMENT 001
}

\section{Adhesives: Test Method, Group Assignment, and Categorization Guide for High-Loading-Rate Applications}

\author{
ARL-ADHES-QA-001.00 rev 1.1 Amendment 00124 July 2017 \\ Amendment 001 replaces ARL standard ARL-ADHES-QA-001.00 rev.1 its entirety to \\ change and update
}

\author{
Change Authority: Robert Jensen \\ Adhesives and Interfaces Research Team \\ Coatings, Corrosion, and Engineered Polymers Branch \\ Materials \& Manufacturing Science Division \\ U.S. Army Research Laboratory \\ RDRL-WMM-C \\ APG, MD 21005
}

\section{Introduction:}

This document was created to provide guidance from the Adhesives and Interfaces Research Team of the Coatings, Corrosion, \& Engineered Polymers Branch (CCEPB) and the U.S. Army Research Laboratory (ARL) for initial performance-based screening evaluation and grouping priority methodology for the assigning/categorizing of candidate adhesives for high-loading-rate applications relevant to U.S. Army needs.

This standard has been technically reviewed by two ARL reviewers external to the Adhesives and Interfaces Research Team. Reviewed by Chief, CCEPB. OPSEC approved for public release; distribution unlimited. Administrative and operational procedures for continuation beyond the Second Tier of testing and characterization are omitted.

\section{Purpose for Change:}

Elevated temperature single-lap-joint strength retention modified to 50\% based on acceptance standards for aerospace adhesives (AMS3686A ${ }^{1}$, AMS3692C $^{2}$, and AMS3695/43).

\footnotetext{
${ }^{1}$ AMS3686A. Adhesive, polyimide resin, film and paste high temperature resistant, $315^{\circ} \mathrm{C}\left(599{ }^{\circ} \mathrm{F}\right)$. Warrendale (PA): SAE International; 2008.

${ }^{2}$ AMS3692C. Adhesive compound, epoxy resin high temperature application. Warrendale (PA): SAE International; 2014.

${ }^{3}$ AMS3695/4. Adhesive film, epoxy-base, high durability for $215^{\circ} \mathrm{C}\left(420^{\circ} \mathrm{F}\right)$ service. Warrendale (PA): SAE International; 2014.
} 
Summary of Changes to Standard:

SECTION CHANGED

8.3.2.1 Requirements

\section{DESCRIPTION OF CHANGE}

Decreased single-lap-joint strength retention at elevated temperature from $75 \%$ to $50 \%$ of dry maximum strength, per 8.3.2.1, as proposed by experimental results discussed in ARL-TR-8011.5

\section{Authorization Signatures:}

Originator:_ Dertert Dassen Date: $9 / 7 / 17$

CCEPB Quality Assurance Coordinator: Chasles Pegentie Date: $9 / 21 / 2017$

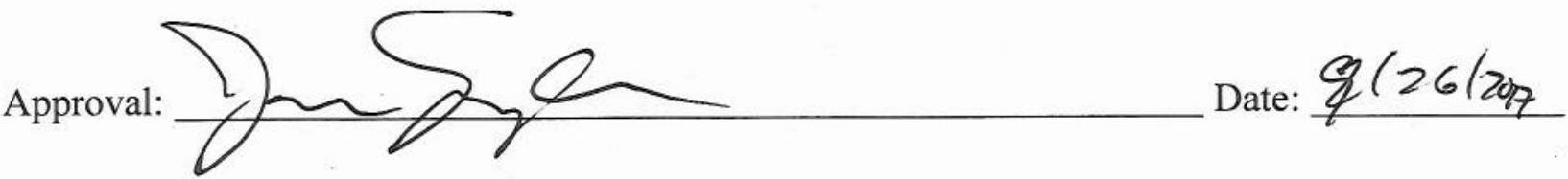

${ }^{4}$ Jensen R, Flanagan D, DeSchepper D, Silton M. Single-Lap-Joint Screening of Hysol EA 9309NA Epoxy Adhesive. Aberdeen Proving Ground (MD): Army Research Laboratory (US); 2017 May. Report No.: ARL-TR-8011. 


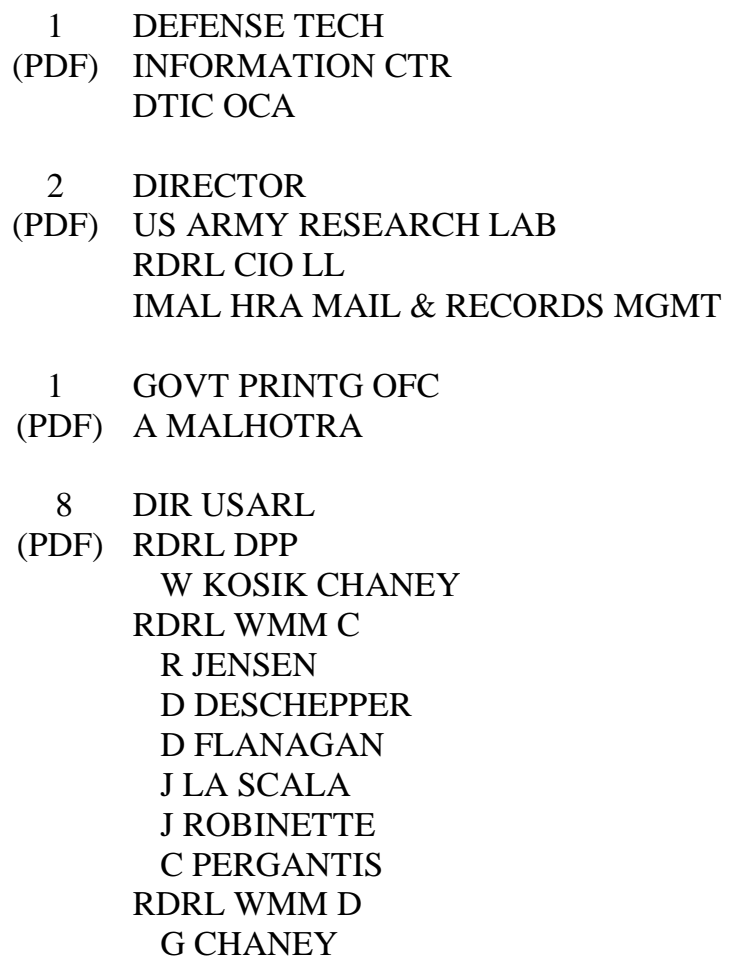

